\title{
Deformation mechanisms under shallow foundations on liquefiable layers of varying thickness
}

\author{
O. ADAMIDIS* AND S. P. G. MADABHUSHI*
}

\begin{abstract}
Structures with shallow foundations resting on liquefiable layers can suffer excessive settlement in the event of an earthquake. The state of practice often estimates the settlement of structures using empirical methodologies. Commonly, these are based on case histories or estimations developed for the free-field. Their reliability has been contested due to uncertainties regarding the dominant deformation mechanisms in the presence of a structure. Here, six dynamic centrifuge tests are presented, investigating the response of structures with shallow foundations resting on liquefiable layers of different thickness. Particle Image Velocimetry (GeoPIV) was used to capture the developed deformation mechanisms. A structure resting on a deep liquefiable layer was found to settle primarily due to increased lateral soil displacements taking place beneath a bulb of stiffer soil formed below the foundation. In shallower layers, this bulb reached the base of the layer, transmitting large accelerations to the structure and promoting a rocking response. Settlement in this case was generated due to increased soil displacement from under the edges of the foundation. In no case were methodologies aimed for the free-field able to account for the salient settlement-generation mechanisms.
\end{abstract}

KEYWORDS: liquefaction; shallow foundations; settlement; deformation mechanisms

\section{INTRODUCTION}

Buildings with shallow foundations resting on liquefiable layers can suffer severely in the event of an earthquake. Despite being the most common, these buildings are not sufficiently protected, even in countries with advanced seismic codes, as showcased during recent events in New Zealand (Cubrinovski et al., 2013), Chile (Bertalot et al., 2013), and Japan (Yasuda et al., 2012).

Settlement is the most sought after aspect of the seismic response of shallow foundations. Yet, its evaluation remains elusive. The state of practice often employs methodologies that predict free-field displacements and only account for sedimentation and consolidation in order to attain estimations of settlement (e.g. Tokimatsu \& Seed, 1987; Ishihara \& Yoshimine, 1992). However, several additional mechanisms have been identified as contributing to settlement in the presence of shallow foundations. Dashti et al. (2010) attributed additional volumetric strains to localised partial drainage and diminishing effective stresses. They also stressed the importance of deviatoric strains, due to partial bearing failure or ratcheting of the structure.

Despite the conceptual identification of settlementgenerating mechanisms, their case-specific significance remains unclear. Of all important parameters, the depth of soil that liquefied $\left(D_{L}\right)$ has received most attention over the years, notably through the empirical graph introduced by Yoshimi \& Tokimatsu (1977) and later enriched with centrifuge test results by Liu \& Dobry (1997). This graph links

\footnotetext{
*Schofield Centre, University of Cambridge, CB3 0EL, United Kingdom
}

the width of the building $(B)$ normalised by $D_{L}$, to a range of expected settlement $(S)$ also normalised by $D_{L}$ (fig. 3). This graph is commonly used in practice to provide estimations of settlement. However, its validity for thin layers was recently challenged by Dashti et al. (2010) and Bertalot et al. (2013). The main issue seems to be an inherent bias in favour of volumetric strain based mechanisms which could be of limited significance for thinner layers. Further investigation into the deformation mechanisms that contribute to settlement as the depth of liquefied sand decreases is warranted.

In this paper, the deformation mechanisms developed below structures with shallow foundations resting on liquefiable layers are presented, as captured in dynamic centrifuge tests. Settlement evaluation methods are assessed and the way settlement-inducing mechanisms change with the depth of the layer that liquefied and the bearing pressure applied by the structure is highlighted.

\section{EXPERIMENTAL METHODS}

The use of centrifuges in geotechnics is well documented (e.g. Madabhushi, 2014). Dynamic centrifuge experiments were chosen because they can realistically recreate the response of liquefiable layers, with the correct stress and strain levels as in the modelled prototype. In addition, provided that viscosity scaling has been performed for the pore fluid, the drainage conditions and soil-structure interaction can both be accurately incorporated. The focus of this paper is on the ultimate deformation mechanisms, depicting the displacements accumulated at the end of an earthquake. 
Six centrifuge tests are presented, performed on the Turner Beam Centrifuge of the Schofield Centre, at the University of Cambridge. They modelled the plane strain problem of a shallow, strip foundation resting on a layer of fully saturated, loose, liquefiable sand. Cross-sections of the models are presented in figure 1.

A centrifugal acceleration of $50 \mathrm{~g}$ was applied at the level of the foundations. All structures examined had the same foundation width ( $B=4.6 \mathrm{~m}$ in prototype scale) and the same aspect ratio $\left(h_{C M} / B=0.58\right.$, where $h_{C M}$ is the height of the centre of mass, measured from the base of the foundation). The depth of the liquefiable layer and the bearing pressure applied by the foundation were altered for each test as detailed in table 1. Overall, three values of normalised width $\left(B / D_{L}\right)$ and two values of bearing pressure $(q)$ were examined.

Table 1. Details for the centrifuge tests.

\begin{tabular}{llll}
\hline Test ID & $\begin{array}{l}\text { Normalised } \\
\text { width } \\
B / D_{L}\end{array}$ & $\begin{array}{l}\text { Bearing } \\
\text { pressure } \\
q(\mathrm{kPa})\end{array}$ & $\begin{array}{l}\text { Structure } \\
\text { type }\end{array}$ \\
\hline OA4 & 0.4 & 50 & $\mathrm{a}$ \\
OA5 & 0.4 & 100 & $\mathrm{~b}$ \\
OA6 & 1 & 50 & $\mathrm{a}$ \\
OA7 & 1 & 100 & $\mathrm{~b}$ \\
OA8 & 2 & 50 & $\mathrm{a}$ \\
OA10 & 2 & 100 & $\mathrm{~b}$ \\
\hline
\end{tabular}

A rigid model container was used, one side of which included a Perspex window, making a cross-section of the model visible. This cross-section was monitored with a high frame-rate MotionBLITZ EoSens mini2 camera. The Perspex was polished before each experiment to obtain a smooth surface. It is assumed that friction at the interface of the Perspex and the soil was low enough to consider the captured images characteristic for the plane strain models. While a rigid box was necessary in order to include a Perspex window, its walls could introduce significant boundary effects. In an effort to reduce boundary effects, a material called Duxseal was placed at the edges of the box, as shown in figure 1. Its effectiveness was examined by Steedman \& Madabhushi (1991), who concluded that it is able to absorb about $65 \%$ of incident wave energy for $\mathrm{P}$ and $\mathrm{S}$ waves.

Sand layers were prepared by air pluviation of Hostun sand, using the automatic sand pourer described by Madabhushi et al. (2006). The targeted relative density was $40 \%$. Properties of Hostun sand are shown in table 2, following Mitrani (2006). Instruments were included within the soil layers, as shown in figure 1 . The instrumentation consisted of miniature piezoelectric accelerometers (Acc), microelectromechanical system accelerometers (MEMS), pore pressure transducers (PPTs), and linear variable displacement transducers (LVDTs).

The model was saturated using a high viscosity aqueous solution of hydroxypropyl methylcellulose, prepared as described in Adamidis \& Madabhushi (2015). A viscous solution was used in order to overcome the inconsistency
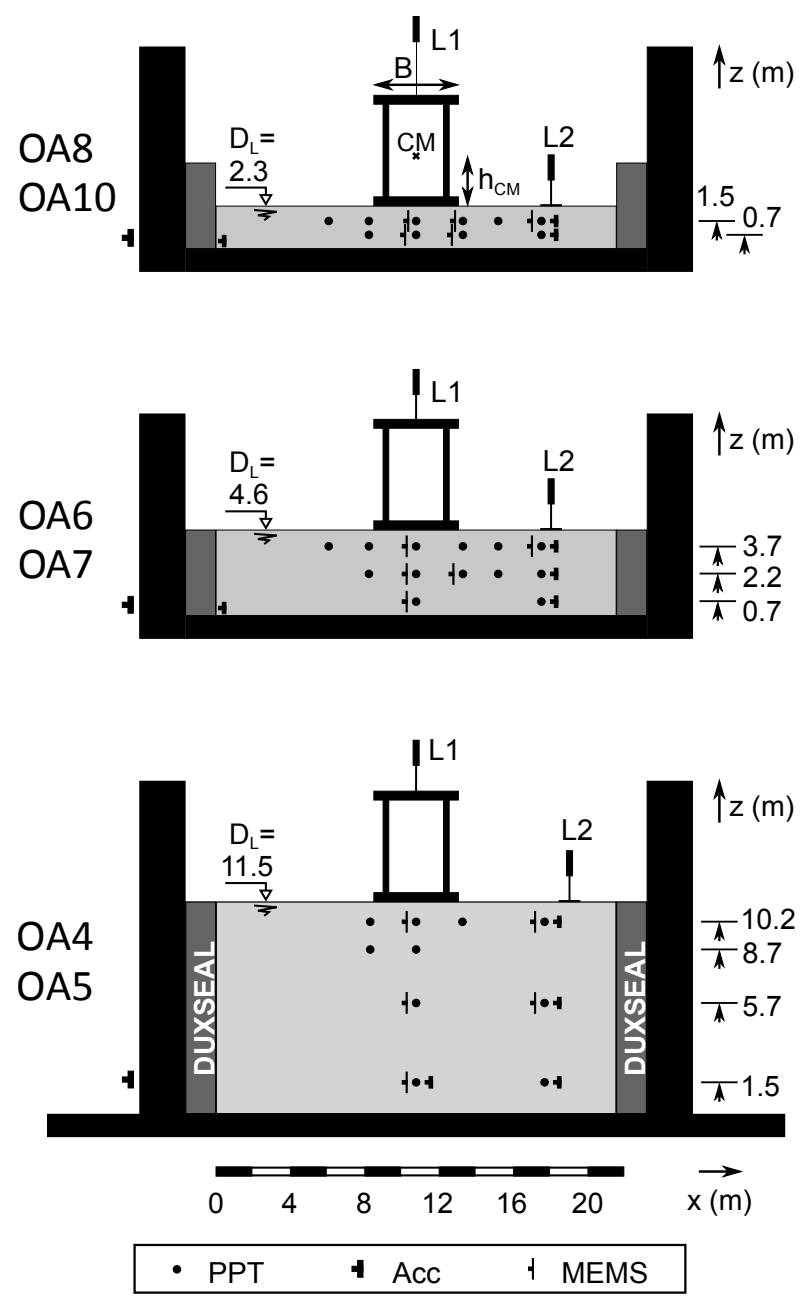

Fig. 1. Cross-section sketches of centrifuge experiments. Dimensions in prototype scale.

Table 2. Properties of Hostun sand (reproduced from Mitrani (2006)).

\begin{tabular}{llll}
\hline$e_{\max }$ & $e_{\min }$ & $G_{S}$ & $\phi_{\text {crit }}$ \\
\hline 1.010 & 0.555 & 2.65 & $33^{\circ}$ \\
\hline
\end{tabular}

between the scaling laws of dynamic and seepage time in centrifuge modelling (Madabhushi, 2014). The applied centrifugal acceleration was $50 \mathrm{~g}$, so the targeted viscosity of the pore fluid was $50 \mathrm{cSt}$. The saturation of the model was performed using a computer controlled system expected to yield a degree of saturation of $98 \%$ to $99 \%$ (Stringer \& Madabhushi, 2009).

The two structures examined corresponded to plane strain conditions. Cross-section sketches of structures (a) and (b) are given in figure 2 . Their mass and aspect ratio $\left(h_{C M} / B\right)$ were adjusted with the addition of brass plates. Their aspect ratio remained the same so as to isolate the effects of the depth of the liquefiable layer and the bearing pressure. Moreover, their fixed-base frequency was selected to be higher than the frequency of the input motion, to promote a rigid-object type of response and simplify the problem. The friction angle at the 

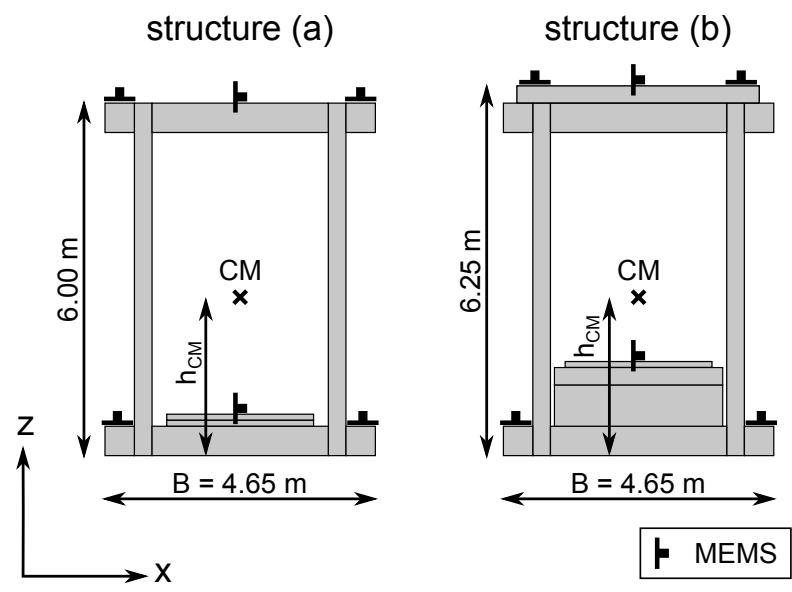

Fig. 2. Cross-section sketches of structures (a) and (b). Dimensions in prototype scale.

interface between the structures and the sand was measured using direct shear tests and was $\delta=28.8^{\circ}$. The properties of the structures are detailed in table 3 .

Table 3. Properties of structures, in prototype scale.

\begin{tabular}{llll}
\hline Structure & $\begin{array}{l}\text { Bearing } \\
\text { pressure } \\
(\mathrm{kPa})\end{array}$ & $\begin{array}{l}\text { Aspect } \\
\text { ratio } \\
\left(h_{C M} / B\right)\end{array}$ & $\begin{array}{l}\text { Fixed-base } \\
\text { frequency } \\
(\mathrm{Hz})\end{array}$ \\
\hline $\mathrm{a}$ & 50 & 0.58 & 7.4 \\
$\mathrm{~b}$ & 100 & 0.58 & 5.9 \\
\hline
\end{tabular}

The input motions were pseudo-harmonic, generated by the Stored Angular Momentum (SAM) actuator described in Madabhushi et al. (1998). The targeted duration was $20 \mathrm{~s}$ and the targeted frequency was $1 \mathrm{~Hz}$, both in prototype scale. The amplitude of the input acceleration was about $0.2 \mathrm{~g}$ in prototype scale. These input motions are included in figure 5. During test OA10, only the first $12 s$ of the earthquake were applied due to a malfunction of the SAM actuator. However, test OA10 can still be compared to the first $12 s$ of test OA8.

Particle Image Velocimetry (GeoPIV) analysis was performed to obtain displacement fields within the visible soil section (White et al., 2003). The images captured varied in size as the layers changed in depth. For OA4 and OA5 the image size was $1696 \times 990$ pixels, for OA6 and OA7 it was $1696 \times$ 810 pixels, and for OA 8 and OA10 it was $1696 \times 500$ pixels. The resolution of the images was limited due to the dynamic camera used, which could however capture images at a very high frame rate. Roughly, for the images captured, 5.8 pixels corresponded to $1 \mathrm{~mm}$ in model scale. The frequency at which images could be captured was dependent on the image size. For OA4 and OA5 images were captured at $900 \mathrm{~Hz}(18 \mathrm{~Hz}$ in prototype scale), for OA6 and OA7 they were captured at 1108 $\mathrm{Hz}(22.16 \mathrm{~Hz}$ in prototype scale), and for OA8 and OA10 they were captured at $1790 \mathrm{~Hz}(35.8 \mathrm{~Hz}$ in prototype scale). In all cases the exposure time was $76 \mu \mathrm{s}$. The 'patches' tracked using GeoPIV were of $50 \times 50$ pixels and were spaced at 25 pixels, overlapping each other to give a denser mesh of tracked points.
Experimental methods are described in more detail in Adamidis (2017).

\section{SETTLEMENT EVALUATION METHODS}

The empirical graph suggested by Liu \& Dobry (1997) is commonly used in practice to provide estimates of the settlement of structures. Methodologies developed for the freefield are also often used for comparison. Estimations using these methods are compared to centrifuge test results in table 4. In all of the centrifuge tests examined here, the depth of the soil that liquefied $\left(D_{L}\right)$ was the same as the depth of the layer.

The method of Tokimatsu \& Seed (1987) estimated large volumetric contraction of about $3 \%$ for all tests. In all cases, the method underestimated the actual settlement of the structure. As the depth of the layer decreased, the values calculated deviated further from the observed settlement.

The method of Ishihara \& Yoshimine (1992) led to the estimation of even larger volumetric contraction, of about $4.5 \%$. Even though the value for OA4 was not far off the settlement of the structure, estimations for the rest of the tests were not accurate.

While free-field methodologies failed to offer reliable estimations for the settlement of structures, they remain useful for their original purpose. Indeed, the settlements estimated were not far from the observed settlements away from the structures (last column of table 4). Tests OA4 and OA5 should not be considered in this comparison, as in these experiments the extent of structure-induced deformations was such that even soil at the edges of the box was affected.

The third method considered was the empirical graph that relates the normalised width of a structure $\left(B / D_{L}\right)$ with the expected normalised settlement $\left(S / D_{L}\right)$, as introduced by Yoshimi \& Tokimatsu (1977) and presented by Liu \& Dobry (1997). Settlement measurements from the centrifuge tests presented here were plotted on this graph in figure 3, along with results from previous publications. The range of settlement estimated by this method can be large enough to render it of limited use for deep layers. Despite their large range, estimations were still not particularly successful. For tests OA4 and OA5, where $B / D_{L}=0.4$, the actual settlement fell just below the predicted zone. For tests OA6 and OA7, where $B / D_{L}=1$, the building settlement was within the predicted range. For the very thin layers of tests OA8 and OA10, where $B / D_{L}=2$, the observed settlement was significantly higher than anticipated. Similar results were obtained for the other centrifuge tests included in figure 3. Evidently, the use of this graph cannot be encouraged for high ratios of $B / D_{L}$.

Lastly, the method proposed by Bertalot et al. (2013) for the estimation of an upper limit of expected settlement was examined. As this methodology is recent, its use in practice is not yet common. The upper bounds calculated according to it were valid for the earthquakes applied here, which contained a large number of strong cycles. The estimated upper bounds 
Table 4. Estimations of settlement evaluation methods in comparison to experimental settlement (in prototype scale).

\begin{tabular}{|c|c|c|c|c|c|c|}
\hline Test ID & $\begin{array}{l}\text { Tokimatsu \& } \\
\text { Seed (1987) } \\
\text { Settlement } \\
(\mathrm{cm})\end{array}$ & $\begin{array}{l}\text { Ishihara \& } \\
\text { Yoshimine } \\
(1992) \\
\text { Settlement } \\
\text { (cm) }\end{array}$ & $\begin{array}{l}\text { Liu \& Dobry } \\
\text { (1997) } \\
\text { Settlement } \\
\text { (cm) }\end{array}$ & $\begin{array}{l}\text { Bertalot et } \\
\text { al. (2013) } \\
\text { Settlement } \\
(\mathrm{cm})\end{array}$ & $\begin{array}{l}\text { Measured at } \\
\text { structure: } \\
\text { Settlement } \\
(\mathrm{cm})\end{array}$ & $\begin{array}{l}\text { Measured at } \\
\text { field: } \\
\text { Settlement } \\
(\mathrm{cm})\end{array}$ \\
\hline OA4 & 33 & 50 & $88-387$ & 94 & 46 & 1 \\
\hline OA5 & 33 & 50 & $88-387$ & 146 & 77 & -10 \\
\hline OA6 & 12 & 20 & $9-76$ & 74 & 50 & 12 \\
\hline OA7 & 12 & 20 & $9-76$ & 109 & 52 & 9 \\
\hline OA8 & 7 & 10 & $0-9$ & 51 & 33 & 9 \\
\hline OA10 & 7 & 10 & $0-9$ & 67 & 27 & 13 \\
\hline
\end{tabular}

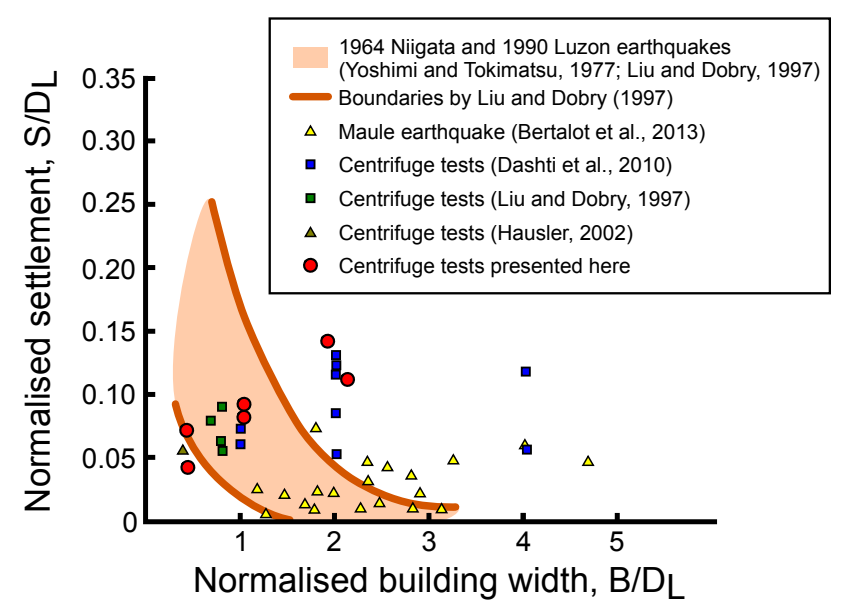

Fig. 3. Empirical graph, relating the width of the foundation $B$ with its settlement $S$, both normalised with the depth of the layer that liquefied $D_{L}$.

for settlement were up to two times larger than the observed settlements, except for test OA10, where the earthquake was shorter and the upper bound was 2.5 times larger than the observed settlement.

\section{OVERVIEW OF RESPONSE}

In order to verify that the structures can be assumed to have behaved as rigid objects, the input acceleration recorded at the base of the box as well as the acceleration recorded at the top mass of the structure are both presented in figure 4. Large Fourier components corresponded to the same frequencies for both acceleration recordings presented, indicating that the structure responded at the frequency of the input motion and did not significantly oscillate at another frequency. The frequencies excited by the input motion lied far from the fixed base frequency of the structures, measured before and after each experiment and also shown in figure 4. As anticipated for these stiff structures resting on liquefiable soil that softened during the earthquakes, flexural response was negligible.

The response of the structures examined in the centrifuge is outlined in figure 5. The time histories of settlement, inclination (including initial rotation), and foundation embedment are presented. The settlement corresponds to the vertical displacement of the structures, measured by LVDT L1 (fig. 1). Inclination was calculated using GeoPIV results, considering the counterclockwise direction as positive. The average of embedment at the two edges of the foundation is shown, including pre-seismic embedment. Finally, the time histories of input acceleration and corresponding Arias intensity (Arias, 1970) are given, to indicate that very similar input motions were imposed for tests with the same value of $B / D_{L}$. Arias Intensity roughly corresponds to the energy input of the excitation.

In figure 6 the Arias intensity of the motions applied in OA4 and OA6 are compared to two well studied seismic records: record TCU068 (ns) of the Chi-Chi earthquake of 1999 and record Takatori (000) of the Kobe earthquake of 1995. While the earthquakes applied in the centrifuge included many cycles of rather strong shaking, they should not be considered of unrealistic intensity. Indeed, as showcased in particular by the Takatori record, it is possible for earthquakes to reach much higher levels of Arias intensity significantly faster.

For $B / D_{L}=0.4$, the settlement accumulated by the heavy structure of OA5 was significantly larger than that of the light structure of OA4, despite the input motions being very similar. In both cases, post-earthquake settlements were minimal. Both structures exhibited significant rotation during the first cycle of loading, which diminished in subsequent cycles. The light structure of OA4 maintained the trend of diminishing rotational oscillations until the end of the earthquake, while also accumulating permanent rotation. The heavy structure of OA5 responded differently after the first eight cycles. At that point, Arias Intensity has reached a value of about 1 $\mathrm{m} / \mathrm{s}$. The structure transitioned towards a rocking response, with gradually increasing rotational oscillations. No significant permanent rotation was accumulated. This transition towards a rocking response is expected to have been aided by the increasing embedment in OA5, which offered better coupling between the foundation and its surrounding soil.

For $B / D_{L} \geq 1$, differences in the weight of the structures did not result in significant differences in settlement. As for deeper layers, additional, post-earthquake settlement was minimal. For all layers where $B / D_{L} \geq 1$, large rotational oscillations were recorded at the foundation. The lighter structures of OA6 and OA8 gradually increased their rotational 


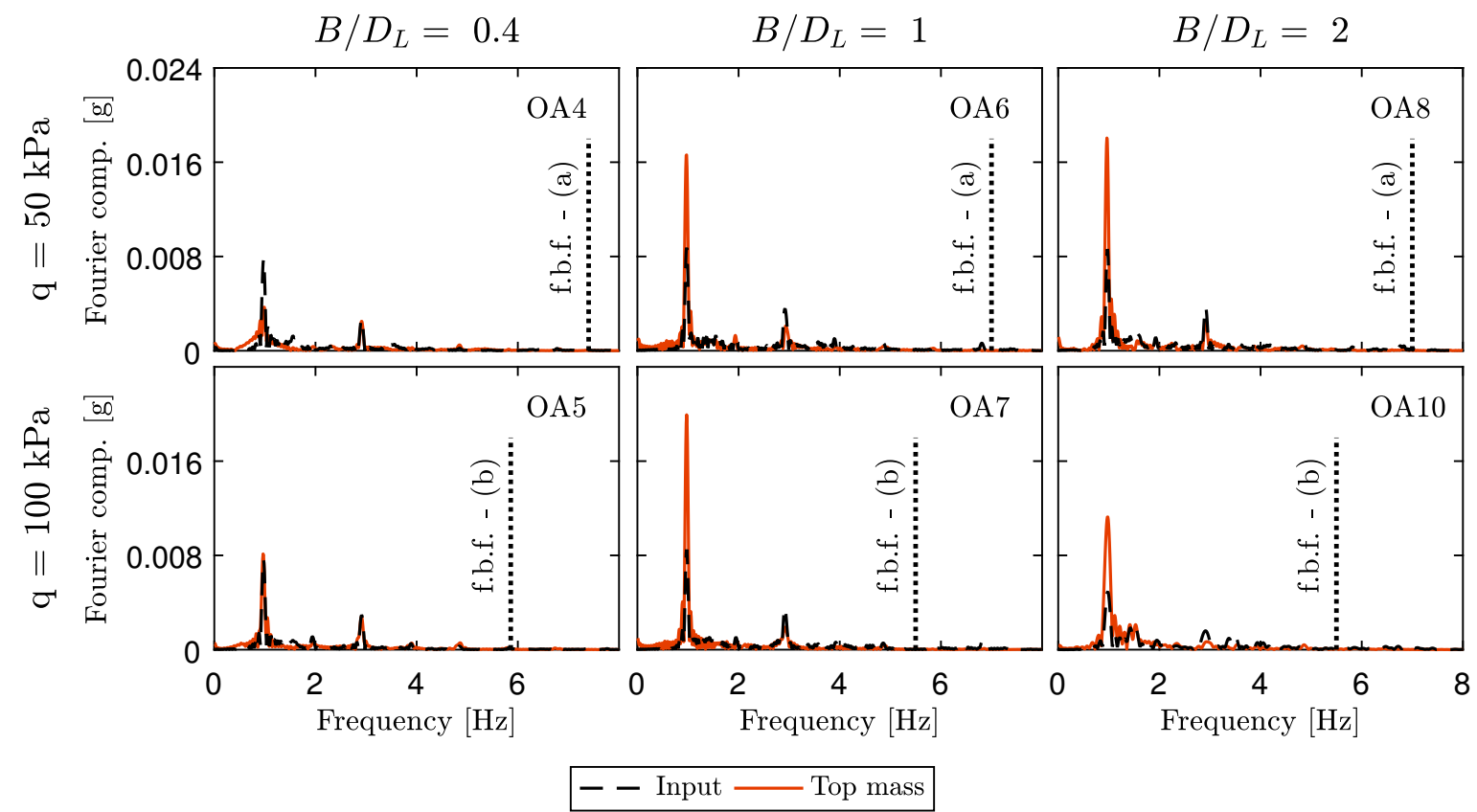

Fig. 4. Fast Fourier Transform (FFT) of acceleration at the base of the box and at the top of the structures. The fixed base frequency (f.b.f.) of the structure (a or b) used in each experiment is included as a dotted line. Units in prototype scale.

amplitude, which reached a fairly constant value after about six cycles. The heavy structures of OA7 and OA10 attained practically constant values of rotational oscillation amplitude after the first two cycles. All structures accumulated some positive (counter-clockwise) rotation during the earthquake. The heavier structures gained increased embedment at the very beginning of the excitation but once a rocking response had been established, the rate of embedment accumulation was similar for structures of different weight.

Bray \& Dashti (2014) proposed a new measure of intensity called SIR (Shaking Intensity Rate) for the evaluation of settlement, which represents the rate of Arias intensity buildup. Here, it would correspond to the slope of the Arias intensity lines of figure 5. They suggested using the SIR and the relative density of liquefiable sand layers to predict the settlement of a structure with shallow foundations. Considering the difference in settlement between OA4 and OA5, despite the relative density and the SIR being similar, it can be inferred that the bearing pressure imposed by the structure must also be considered. However, its effect is dependent on the ratio of $B / D_{L}$, as pointed out by Bertalot et al. (2013). Here, the effect of bearing pressure becomes not evident for the two structures examined if $B / D_{L} \geq 1$.

\section{TOTAL SOIL DISPLACEMENTS}

The GeoPIV-calculated displacement fields developed within the examined liquefiable layers are shown in figure 7 . It should be noted that these fields correspond to accumulated co-seismic displacement, as the camera had a limited memory capacity and could not capture all of the post-seismic response. However, as already stated, in all cases post-seismic displacements were minimal for the structures (fig.5).

Deep layers, $B / D_{L}=0.4$

The displacement vectors depict an extended mechanism for the deep layers of OA4 and OA5. The area monitored by the camera, $3 B$ in length and $1.4 B$ in depth, did not encompass the whole cross-section of the model. The increase in bearing pressure in OA5 led to displacement vectors of increased magnitude. Under the whole width of the footing of OA4, soil moved almost exclusively vertically. While soil also moved down vertically below the heavier footing of OA5, outwards displacements also took place below the edges of the foundation. In both tests, at a horizontal distance of about $0.5 \mathrm{~B}$ from the edges of the foundation and at a depth of about $0.25 \mathrm{~B}$ from the surface, points of zero displacement were observed, around which displacement vectors revolved. The formation of these points might have been aided by the proximity of the vertical boundaries, which were at $0 \mathrm{~m}$ and $22 \mathrm{~m}$ along the abscissa of the graphs of figure 7 .

Horizontal displacements (fig. 8) remained limited below the whole width of the foundation in OA4. This behaviour is consistent with the mechanism suggesting the formation of a bulb of non-liquefied soil below the structure, as proposed by Kawasaki et al. (1998) and also by Ghosh (2003). According to this mechanism, a bulb of non-liquefied soil forms below the structure and large lateral displacement of sand can be expected below it. Ghosh (2003) claimed that it reaches a depth of roughly $2 \mathrm{~B}$. Due to the construction of the window box, the observable depth below the foundation was limited. However, from the shape of the contours of figure 8 it can be inferred 

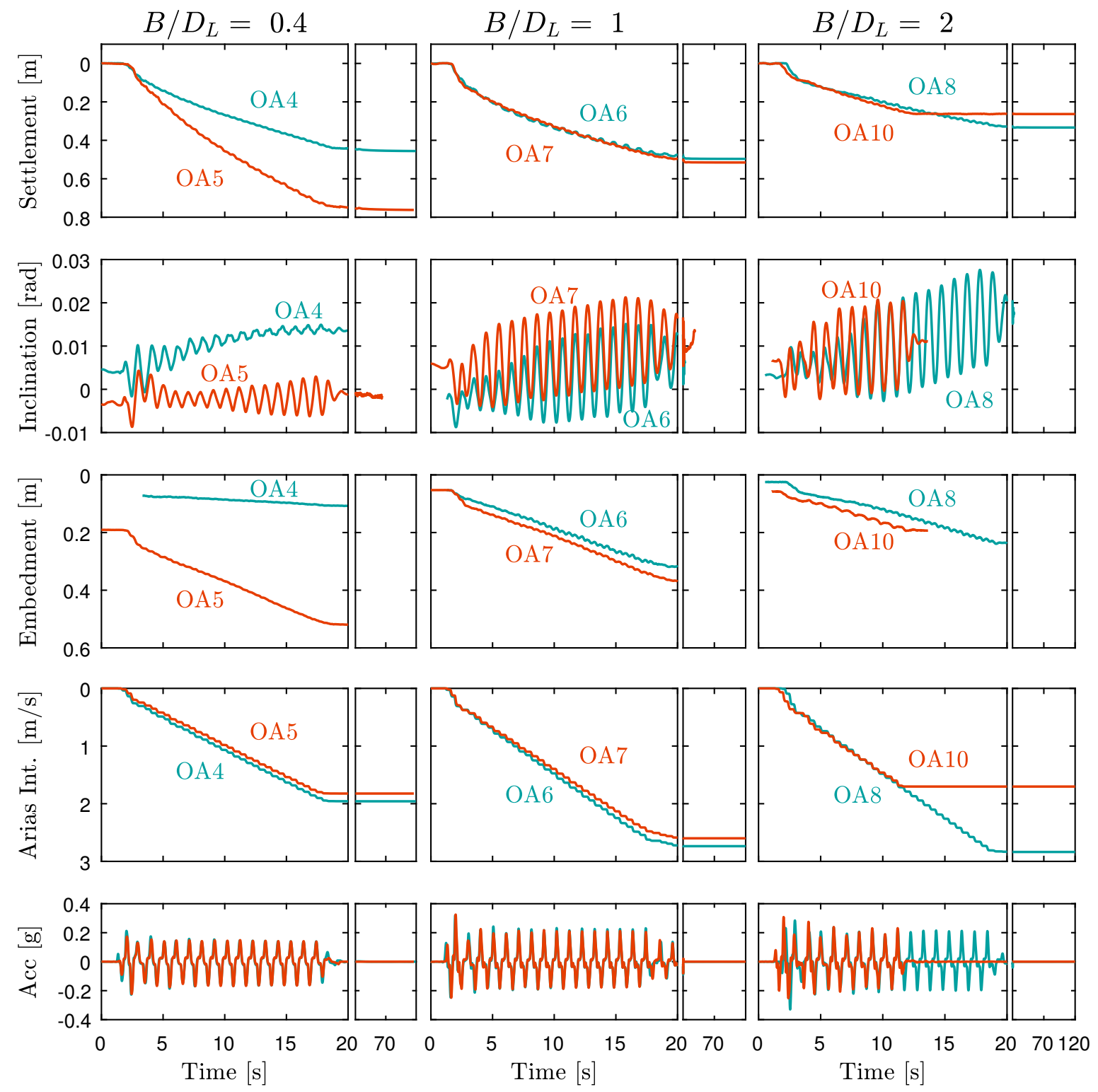

$\mathrm{q}=50 \mathrm{kPa}-\mathrm{q}=100 \mathrm{kPa}$

Fig. 5. Time histories of settlement, inclination (including initial rotation), and embedment of the structures. Counter-clockwise rotation was taken as positive. The time histories of input acceleration and corresponding Arias intensity are also included. Dimensions in prototype scale.

that the maximum horizontal displacement took place at the deepest level observed, at about $1.5 \mathrm{~B}$ below the foundation. The contour of zero displacement did not reach the centre of the foundation. Instead, it diverted to its right edge due to the positive rotation accumulated by the structure throughout the seismic motion.

In OA5, lateral soil displacements of more than $20 \mathrm{~cm}$ occurred at the edges of the soil column below the structure. Maximum horizontal displacements took place at a depth of about $1 B$ and were observed outside of the soil column below the structure. No stark transition to a zone of large horizontal displacement corresponding to softened soil below a nonliquefied bulb was observed. The increased bearing pressure of the structure offered better confinement throughout the soil column below the foundation, not allowing the bulb mechanism to fully manifest. The lack of severe soil softening below the bulb resulted in the structure experiencing larger accelerations, a factor that contributed to the eventual establishment of a rocking response. Rocking led to increased loading of the soil in the vicinity of the foundation's edges, locally increasing displacements. In contrast to OA4, the contour of zero displacement reached the centre of the foundation, reflecting the limited permanent rotation.

The heavier structure of OA5 settled more than its lighter counterpart of OA4, a fact reflected in the contours of vertical displacement of figure 9. The contours were flatter below 


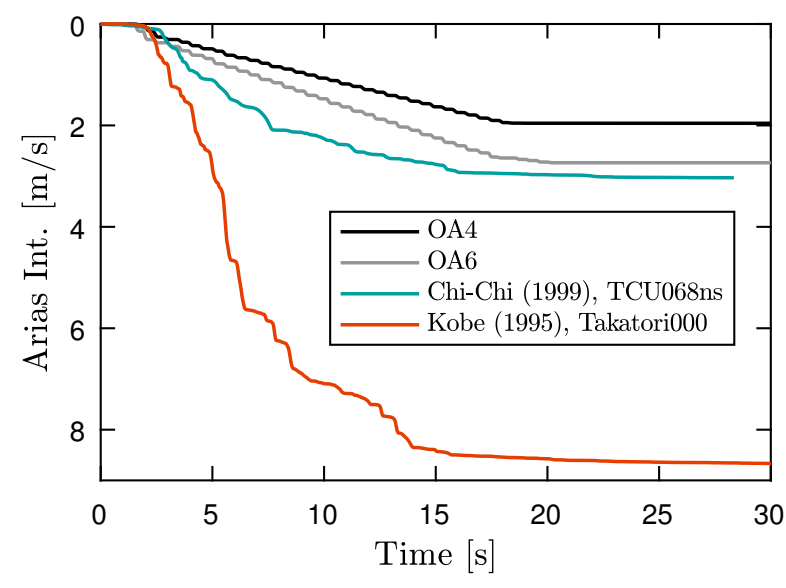

Fig. 6. Comparison of Arias intensity for tests OA4, OA6 and for record TCUO68 (ns) of the Chi-Chi earthquake of 1999 and for record Takatori $(000)$ of the Kobe earthquake of 1995 . Though containing a large number of strong cycles, the applied motions were of realistic intensity. Dimensions in prototype scale.

the structure in OA5, due to the rocking response eventually established, which increased displacements under the edges of the foundation. At the surface of the sand, the area of downwards moving soil was not limited to the foundation but extended further out by about $0.5 \mathrm{~B}$ for both OA4 and OA5. It is useful to note that while a bulb of soil under the examined structures moved downwards in both tests, it did not do so as a rigid body. Vertical displacements gradually decreased within it. Further away from the structure, the displaced soil diverted upwards, possibly aided by the proximity of the boundaries.

A simplified sketch for the deformations developed within the deep liquefiable layers is shown in figure 10a. It is proposed that a bulb of stiffer soil formed below the structure, extending to a depth of about $1 \mathrm{~B}$. As the fully liquefied areas surrounding the soil column below the structure could not offer any significant support, soil was displaced around and especially below the bulb and settlement was generated. This mechanism is considered appropriate for typical earthquakes, where the number of strong cycles is less than eight. In the case of an earthquake with more strong cycles, a light structure will maintain this type of response, as in OA4. Nevertheless, the higher accelerations transmitted through the better confined soil column beneath a heavy structure can eventually force a rocking response. The accumulation of embedment is important for the realisation of this transition. If this happens, a more localised deformation mechanism can take hold, where settlement is also driven by soil displacements in the vicinity of the edges of the foundation, as in OA5.

Shallow layers, $B / D_{L} \geq 1$

Displacements in the shallow layers examined in tests OA6, OA7, OA8, and OA10 were more localised (fig.7). All structures that rested on layers where $B / D_{L} \geq 1$ responded with rocking. Large soil displacements occurred below the edges of the rocking foundations, with soil moving outwards, towards the free-field. Within the bottom half of the layers, displacements were limited. Doubling the bearing pressure of structures did not have any significant effect on displacement fields.

The horizontal contour plots of figure 8 are similar for all the shallow layers examined but starkly different from those corresponding to the deeper layers of OA4 and OA5. There, maximum horizontal displacements occurred deep within the liquefied layer. Here, they took place beneath the edges of the foundation, driven by structure-induced loading. As the stiffer soil below the foundations reached the base of the layers, larger accelerations were transmitted to the structures, whose aspect ratio promoted a rocking response. Towards the freefield, liquefied soil could not offer significant support, resulting in large horizontal displacements, even one foundation width away from the structure.

The vertical contours of figure 9 also point to a similar settlement-generation mechanism within all shallow layers. A part of the soil below the foundation settled along with the structure. Downward vertical displacements were at a maximum directly below the foundation. By the middle of the layer they had significantly attenuated, taking values below $5 \mathrm{~cm}$. Rather than having the form of a bulb, vertical contours below the foundations were flatter due to the rocking of the structures, which produced large soil displacements below the edges of the foundation. This behaviour was exacerbated for the heavier structures of OA7 and OA10. Also unlike in deeper layers, the area of soil moving downwards did not expand beyond the edges of the foundation. Instead, soil right next to the foundations moved upwards as it was pushed out from under the edges of the structure. Large levels of embedment were produced as a result, which could be particularly hazardous for lifeline connections. In the very shallow layers of tests OA8 and OA10, areas of upwards displacement next to the foundation were very localised. Further out, towards the free-field, the liquefied soil settled, as would be expected.

A simplified sketch of the mechanism observed in shallow layers is shown in figure 10b. The mechanism depicted is reminiscent of a bearing capacity failure mechanism. Displacements are primarily driven by the rotation of the foundation during each half-cycle. As the earthquake advances and the foundations accumulate embedment, the mechanism depicted in figure $10 \mathrm{~b}$ should be expected to become even more localised around the edges of the foundation.

\section{TOTAL SOIL STRAINS}

The total shear and volumetric strains accumulated throughout the earthquakes are shown in figures 11 and 12 respectively, in an effort to offer further insight regarding settlement generation. Shear strains were calculated using GeoPIV, as the change in angle between each set of three neighbouring points which at the beginning of the earthquake formed a right angle. Volumetric strains were calculated as the change in volume 

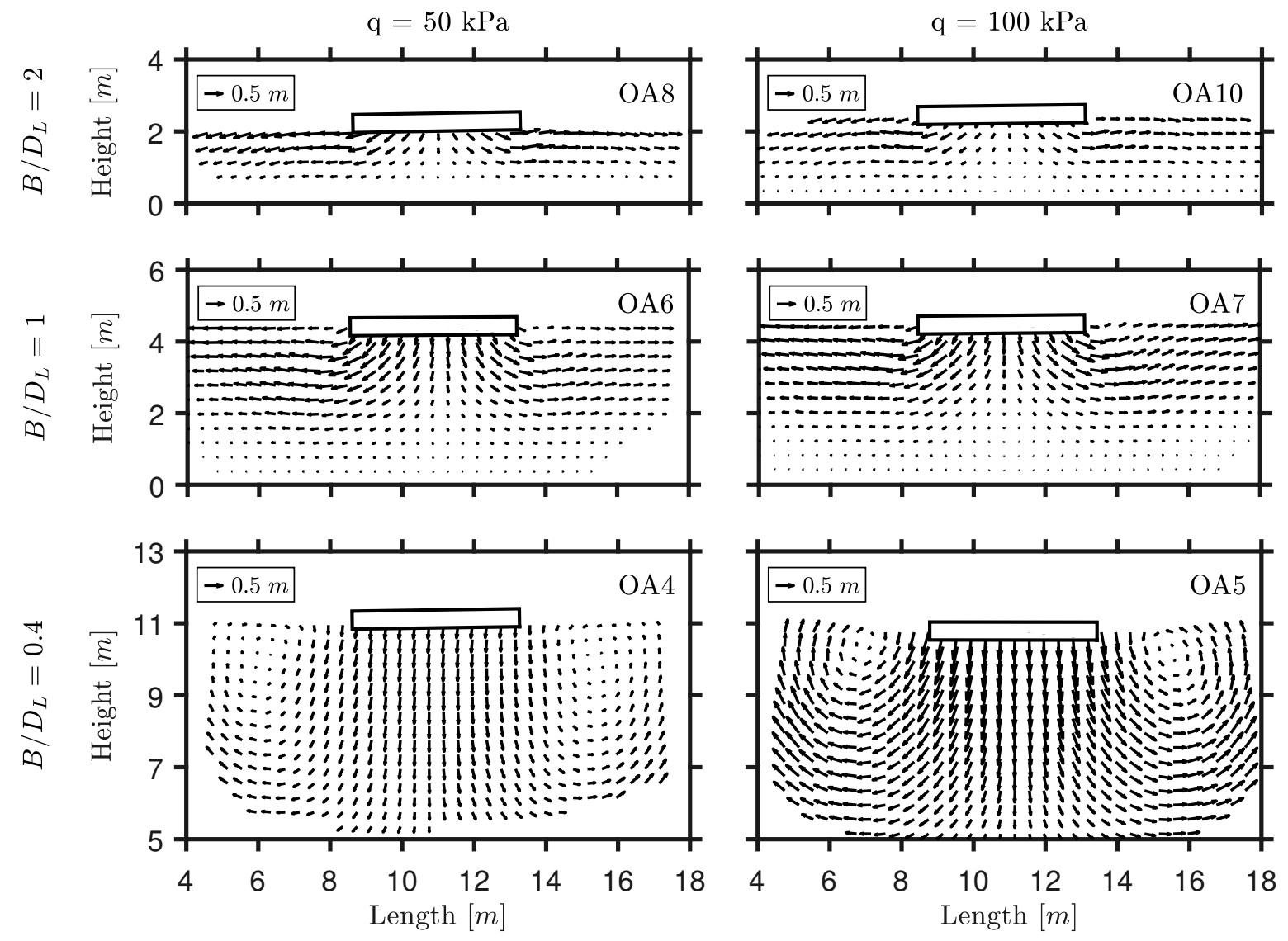

Fig. 7. Accumulated displacement fields at the end of the earthquakes. Dimensions in prototype scale.

of elements whose vertices were tracked by GeoPIV. Positive volumetric strains signify contraction. In the volumetric strain plots presented, areas of volumetric expansion and contraction alternate in a regular pattern. These 'ripples' are likely to appear as an artefact of the GeoPIV analysis algorithm, as detailed by Stanier et al. (2016). Their appearance was likely facilitated by the low particle image size and contrast of the captured images that resulted from the use of a high frame rate camera at low exposure times. Nevertheless, qualitative trends in volumetric strains plots are still discernible.

Deep layers, $B / D_{L}=0.4$

In OA4, where rotations of the structure were small, no significant shear strains were accumulated beneath the footing, throughout the monitored depth. Volumetric strains were also practically zero in this area. Large shearing might have occurred below the observed area, according to the nonliquefied bulb mechanism (Kawasaki et al., 1998; Ghosh, 2003). As the bulb of stiffer soil below the structure moved within the liquefied layer during each half-cycle, it forced the surrounding sand to form active or passive prisms. At the interface of the bulb with these prisms, large shear strains were calculated as well as some volumetric expansion. Further away from the structure, towards the free-field, volumetric contraction was calculated, in particular closer to the surface, where the short drainage path facilitated consolidation.

In OA5, the heavier structure eventually assumed a rocking response. As a result, increased shear strains were recorded in the area below the foundation, up to a depth of about $B / 4$. Within this area, volumetric expansion was also calculated. Outside of the soil column below the structure, large displacements of liquefied soil led to more significant shear strains. Indeed, there is a stark difference in the magnitude of shear strains between the better confined and hence stiffer soil below the foundation and the neighbouring fully liquefied area. Similarly to OA4, large shear strains and some volumetric expansion were accumulated at the interface of the stiffer bulb with the softer, liquefied soil. Away from the structure and close to the surface, consolidation led to volumetric contraction.

Shallow layers, $B / D_{L} \geq 1$

In the shallow layers, shear strains under the centre of the foundations were limited due to the symmetrical mechanism of rocking. Under the edges of the foundations, shear strains 


$$
\mathrm{q}=50 \mathrm{kPa}
$$

Horizontal displacement $[\mathrm{m}]$
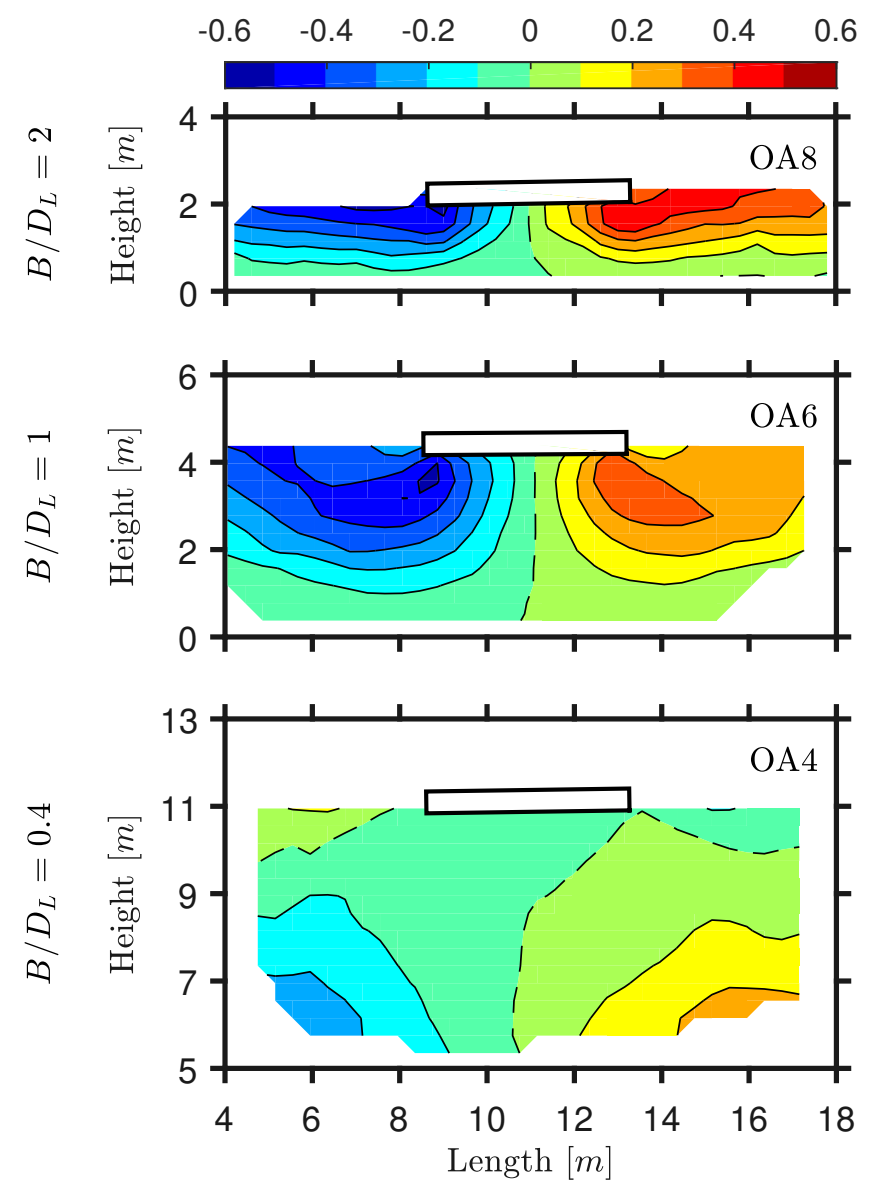

$\mathrm{q}=100 \mathrm{kPa}$

Horizontal displacement $[\mathrm{m}]$
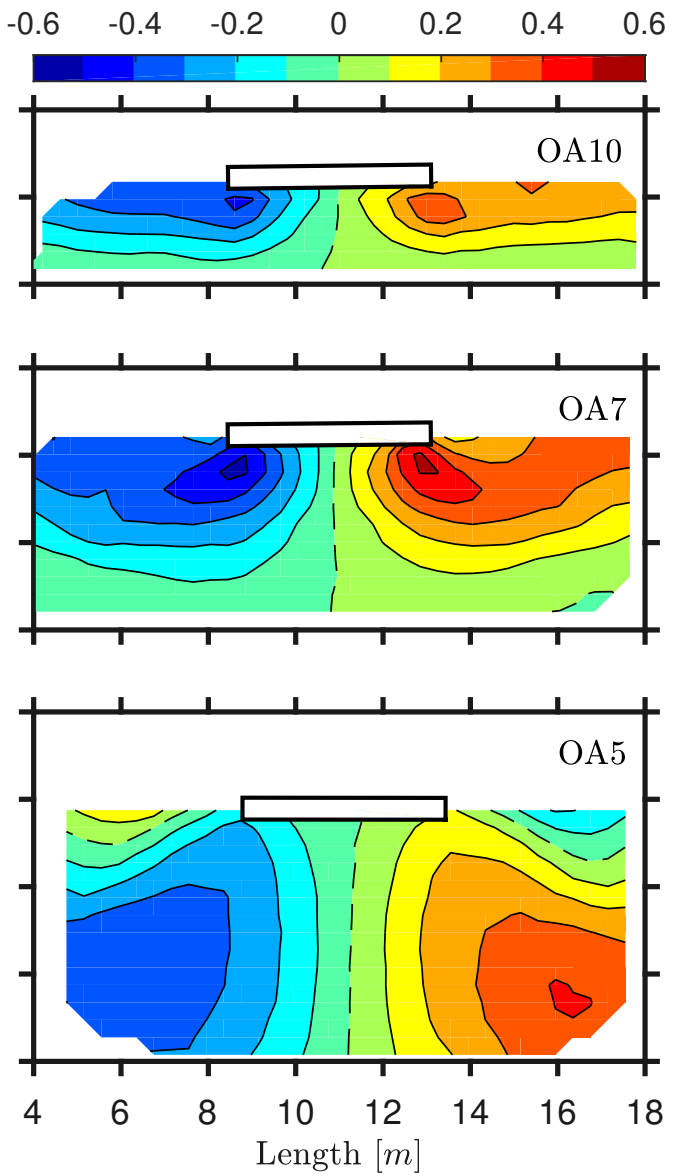

Fig. 8. Contours of accumulated horizontal displacement at the end of the earthquake. The dashed contour lines correspond to zero displacement. Dimensions in prototype scale.

were at a maximum. As the largest soil displacements occurred slightly below the foundations, shear strains above and below that depth had different signs. The location of the depth of maximum displacement was proportional to the depth of the layer and remained insensitive to the bearing pressure of the structures. Increased shear strains were calculated within the soil columns below the structures, especially along their edges, up to a depth practically reaching the base of the layer. Further away from the structures, large levels of shear strain were calculated particularly for the very thin layers of $B / D_{L}=2$.

The trends for volumetric strains were not as clear as for shear strains due to the 'rippling' issue discussed above. However, volumetric expansion was consistently observed below the rocking foundations. This was more prominent below the heavier structures, where driving shear stresses were higher and could push the soil towards a more dilative response (Bertalot \& Brennan, 2015). The accumulation of volumetric expansion showcases why using methodologies that rely on volumetric contraction to predict the settlement of structures resting on thin liquefiable layers can be problematic.
Further away from the structure, volumetric strains were similar to those calculated for the deeper layers of OA4 and OA5. At the interface of the soil column below the foundation with the rest of the layer, some volumetric expansion was accumulated, due to the difference in stiffness between the two areas. Further out, and close to the surface, volumetric contraction was calculated due to reconsolidation of the liquefied sand. Significant contraction was also calculated directly next to the foundations, where the soil was severely sheared as the structures progressively accumulated embedment. The contractive response was due to the lack of driving shear. Indeed, under the edges of the structure, where the soil was also sheared but driving shear was large, dilation occurred and volumetric expansion was calculated.

\section{BOUNDARY EFFECTS}

Due to the extent of the observed deformation mechanisms, the importance of boundary effects has to be examined. In the horizontal direction, the edges of the box were at 0 and $22 \mathrm{~m}$ of the abscissa in figures 7, 8, and 9. The horizontal distance from 


$$
\mathrm{q}=50 \mathrm{kPa}
$$

Vertical displacement $[m]$
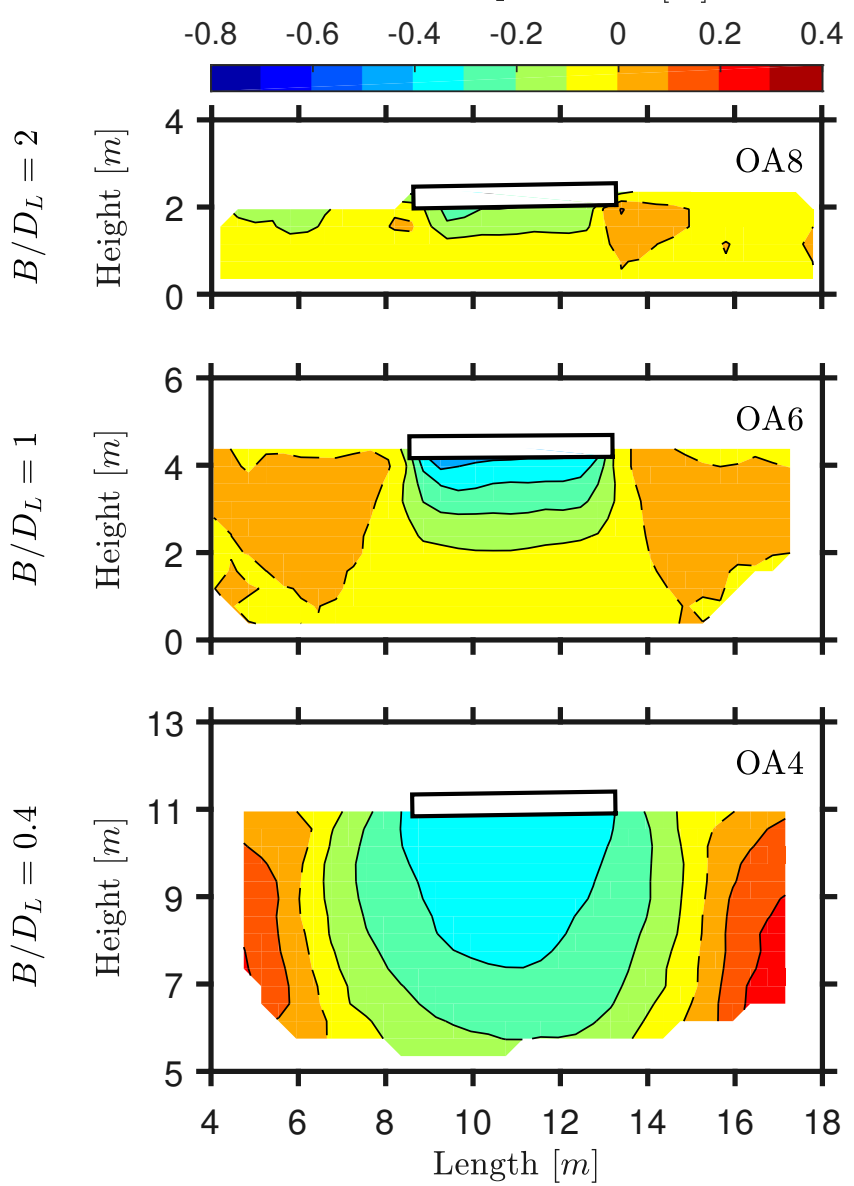

$\mathrm{q}=100 \mathrm{kPa}$

Vertical displacement $[\mathrm{m}]$
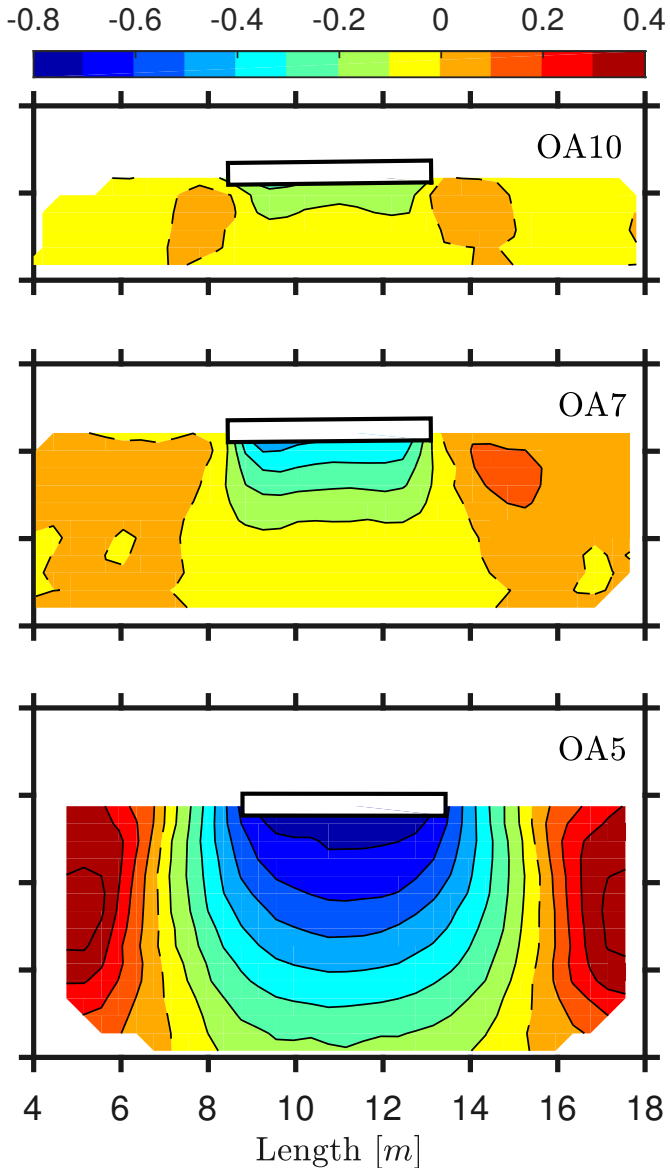

Fig. 9. Contours of accumulated vertical displacement at the end of the earthquake. The dashed contour lines correspond to zero displacement. Dimensions in prototype scale.

each edge of the foundation to the corresponding boundary was about $1.9 \mathrm{~B}$.

For the deep layers of OA4 and OA5, it can be inferred from figure 7 that large displacements reached the boundaries. Indeed, the 'field' surface settlements presented in table 4 and measured next to the boundary were clearly affected by the presence of the structures. In OA5, upwards movement was recorded. Upwards surface displacements could exist and not be due to the presence of the boundaries, as for instance next to the structures of the shallow layers where $B / D_{L} \geq 1$. However, if upwards displacements occurred due to the boundaries, the energy dissipated during this movement could have limited the settlement of the structure. This possibility cannot be ruled out in OA4 and OA5, also bringing into question centrifuge results in literature, where equally low ratios of $\left(B / D_{L}\right)$ were examined with boundaries as close or even closer to the structure. It seems that in order to examine low values of $\left(B / D_{L}\right)$ in a centrifuge, larger than usual levels of centrifugal acceleration need to be used, or smaller prototype foundations need to be examined.
The displacement mechanisms for $B / D_{L} \geq 1$ are not expected to have been significantly affected by the boundaries. Even though horizontal displacements did extend to the edges of the layer (fig. 8), they did not result in significant upwards soil movement there.

\section{CONCLUSIONS}

The focus of this paper was on the deformation mechanisms that develop during an earthquake under shallow foundations resting upon liquefiable layers. Six centrifuge tests were presented, corresponding to three different values of $B / D_{L}$, where $B$ is the width of the foundation and $D_{L}$ is the depth of the layer that liquefied. Two structures were considered for each layer, applying a bearing pressure of $50 \mathrm{kPa}$ or $100 \mathrm{kPa}$.

Within deep layers, where $B / D_{L}=0.4$, a bulb of stiffer soil was maintained below the structure, extending to a depth of about one foundation width. Settlement was accumulated as the surrounding soil was displaced, primarily from underneath the bulb. In the case of the lighter structure, applying a bearing pressure of $50 \mathrm{kPa}$, soil-softening led to increased 


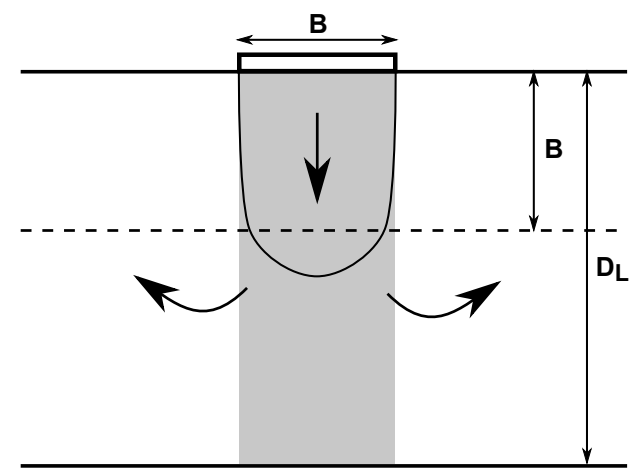

a) Deep layers

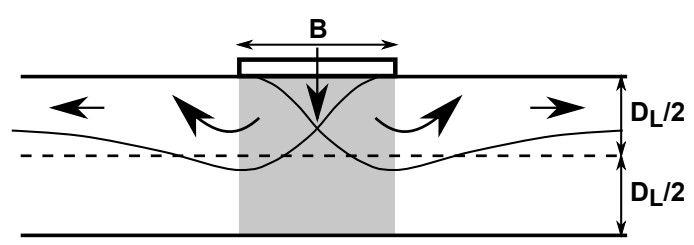

b) Shallow layers

Fig. 10. Sketches of simplified kinematics in a) deep and b) shallow layers. The grey area represents the column of non-liquefied soil below the structure. The depicted mechanisms are expected to apply for typical earthquakes, where the number of strong cycles is less than eight.

lateral displacements within deeper soil. A similar mechanism took place for approximately the first eight cycles of the earthquake when the heavier structure, applying a bearing pressure of $100 \mathrm{kPa}$, was examined. However, soil softening below the bulb was limited in this case, due to the increased confinement applied by the structure. Eventually, the heavy structure accumulated embedment and started responding by rocking, producing a more localised deformation mechanism where settlement was also driven by soil displacements from around the edges of its foundation.

In more shallow layers, where $B / D_{L} \geq 1$, the area of stiffer soil below the structure reached the base of the box, transmitting large accelerations to the structure, which responded by rocking. As in deeper layers, some settlement was due to the liquefied soil of the free-field not being able to laterally support the soil column below the structure. However, settlement here was dominated by the loading imposed by the rocking structure. Large localised displacement of soil from under the edges of the foundation were recorded. Outwards horizontal displacements occurred near the soil surface, even far away from the structure.

Methodologies used in practice to estimate the settlement of structures failed to offer reliable values for the centrifuge tests presented here. The problem was the focus of such methodologies on volumetric mechanisms that affect the whole layer, namely sedimentation and consolidation. In all centrifuge tests examined, the settlement of structures was primarily due to shear strains. Volumetric contraction due to sedimentation or consolidation was in no case a predominant or even a significant contributing factor. On the contrary, volumetric expansion was recorded under rocking foundations. As a result, the use of such methodologies for the estimation of the settlement of structures is discouraged.

Capturing the actual deformation mechanisms developed in liquefiable layers is essential for reliable estimations of structural settlement. Here, insight into what these mechanisms are and how they alter with the depth of the layer and the weight of the structure was offered. Nevertheless, since all structures were of the same aspect ratio $\left(h_{C M} / B=0.58\right)$, its effect was not investigated, although it is expected to be important for the establishment of a rocking response. Moreover, it was pointed out that settlement measurements for ratios of $B / D_{L}=0.4$ might have been affected by the proximity of the boundaries.

\section{ACKNOWLEDGEMENTS}

The centrifuge tests were carried out with the assistance of the technicians of the Schofield Centre, who are hereby acknowledged. The first author would like to thank Qualcomm, the Vergottis family and the Foundation for Education and European Culture for their financial support.

\section{NOMENCLATURE}

$B \quad$ Width of foundation

$D_{L} \quad$ Liquefaction depth

$h_{C M}$ Height of centre of mass of structure, measured from the base of the foundation

$q \quad$ Bearing pressure applied by the structure

$S \quad$ Settlement

$\epsilon_{\text {vol }} \quad$ Volumetric strain

$\gamma \quad$ Shear strain

Acc Piezoelectric accelerometer

LVDT Linear Variable Displacement Transducer

MEMS MicroElectroMechanical systems accelerometer

PIV Particle Image Velocimetry

\section{REFERENCES}

Adamidis, O. (2017). Earthquake-induced liquefaction of sand and response of structures with shallow foundations, $\mathrm{PhD}$ Thesis, University of Cambridge.

Adamidis, O., Madabhushi, S. P. G. (2015). Use of viscous pore fluids in dynamic centrifuge modelling, International Journal of Physical Modelling in Geotechnics, 15(3), pp.141-149.

Arias, A. (1970). A measure of earthquake intensity, Seismic Design for Nuclear Power Plants, MIT Press, pp.438-483. 

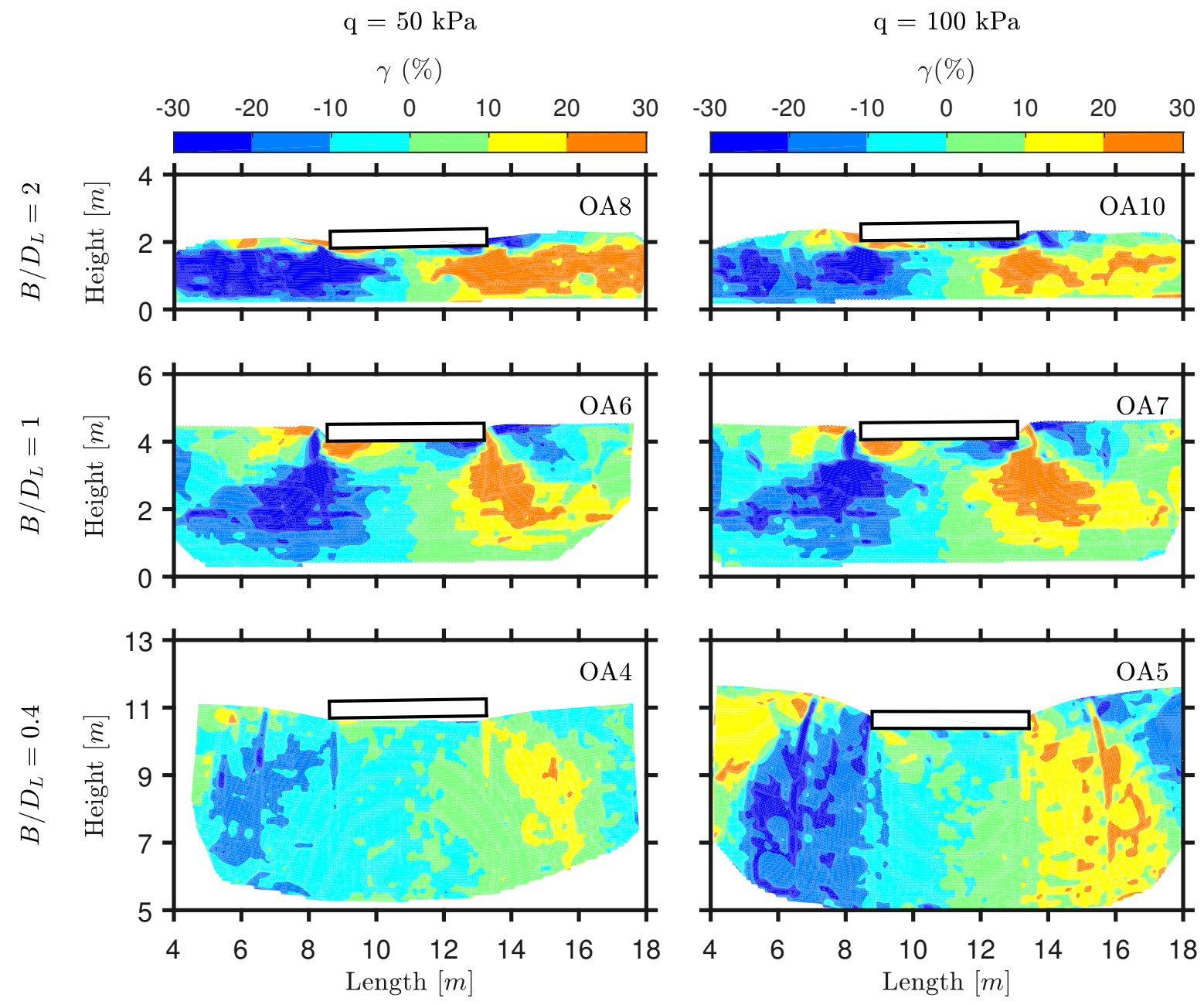

Fig. 11. Contours of total shear strain at the end of the earthquake. Dimensions in prototype scale.

Bertalot, D. \& Brennan, A. J. (2015). Influence of initial stress distribution on liquefaction-induced settlement of shallow foundations, Géotechnique, 65(5), pp.418-428.

Bertalot, D., Brennan, A. J. \& Villalobos, F. A. (2013). Influence of bearing pressure on liquefaction-induced settlement of shallow foundations, Géotechnique, 63(5), pp.391-399.

Bray, J. D. \& Dashti, S. (2014). Liquefaction-induced building movements, Bulletin of Earthquake Engineering, 12(3), pp.11291156.

Cubrinovski, M., Bradley, B., Wotherspoon, L., Green, R., Bray, J., Wood, C., Pender, M., Allen, J., Bradshaw, A., Rix, G., Taylor, M., Robinson, K., Henderson, D., Giorgini, S., Ma, K., Winkley, A., Zupan, J., O'Rourke, T., DePascale, G., Wells, D. (2011). Geotechnical aspects of the 22 February 2011 Christchurch earthquake, Bulletin of the New Zealand Society for Earthquake Engineering, 44(4), pp.205-226.

Dashti, S., Bray, J. D., Pestana, J. M., Riemer, M. \& Wilson, D. (2010). Mechanisms of Seismically Induced Settlement of Buildings with Shallow Foundations on Liquefiable Soil, Journal of Geotechnical and Geoenvironmental Engineering, 136(1), pp.151-164.

Ghosh, B. (2003). Behaviour of rigid foundation in layered soils during seismic liquefaction, $\mathrm{PhD}$ Thesis, University of Cambridge.

Ishihara, K. \& Yoshimine, M. (1992). Evaluation of settlements in sand deposits following liquefaction during earthquakes, Soils and Foundations, 32(1), pp.178-188.

Kawasaki, K., Sakai, T., Yasuda, S., Satoh, M. (1998). Earthquake induced settlement of an isolated footing for power transmission tower, Proc. of The Intern. Conf. Centrifuge '98, Balkema, pp.271276.

Liu, L. \& Dobry, R. (1997). Seismic Response of Shallow Foundation on Liquefiable Sand, Journal of Geotechnical and Geoenvironmental Engineering, 123(6), pp.557-567.

Madabhushi, S. P. G. (2014). Centrifuge Modelling for Civil Engineers, Taylor \& Francis, London.

Madabhushi, S. P. G., Houghton, N. E., Haigh, S. K. (2006). A new automatic sand pourer for model preparation at University of Cambridge, Physical Modelling in Geotechnics, 6th ICPMG'06, Taylor \& Francis, pp.217-222.

Madabhushi, S. P. G., Schofield, A. N., Lesley, S. (1998). A new Stored Angular Momentum (SAM) based earthquake actuator, Proc. of The Intern. Conf. Centrifuge '98, Balkema, pp.111-116.

Mitrani, H. (2006). Liquefaction Remediation Techniques for Existing Buildings, PhD Thesis, University of Cambridge.

Stanier, S., Dijkstra, J., Leśniewska, D., Hambleton, J., White, D., \& Muir Wood, D. (2016). Vermiculate artefacts in image analysis of granular materials, Computers and Geotechnics, 72, pp.100-113. 

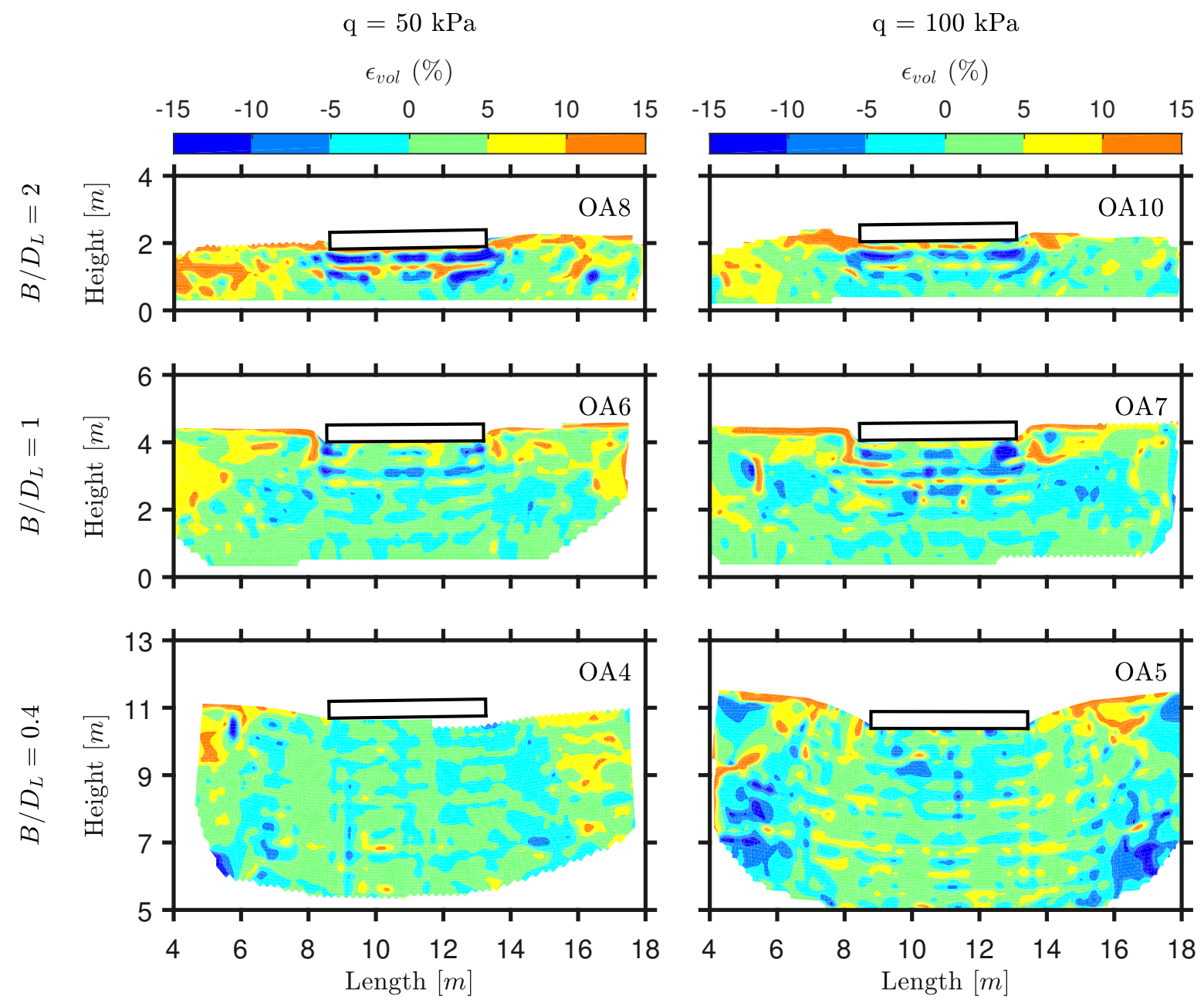

Fig. 12. Contours of total volumetric strain at the end of the earthquake. Dimensions in prototype scale.

Steedman, R. S. \& Madabhushi, S. P. G. (1991). Wave propagation in sand medium, Proc. of Fourth Intl. conference on Seismic Zonation, EERI.

Stringer, M. E. \& Madabhushi, S. P. G. (2009). Novel ComputerControlled Saturation of Dynamic Centrifuge Models Using High Viscosity Fluids, Geotechnical Testing Journal, 32(6), pp.102435.

Tokimatsu, K. \& Seed, H. B. (1987). Evaluation of Settlements in Sands Due to Earthquake Shaking, Journal of Geotechnical Engineering, 113(8), pp.861-878.

Yasuda, S., Harada, K., Ishikawa, K., \& Kanemaru, Y. (2012). Characteristics of liquefaction in Tokyo Bay area by the 2011 Great East Japan Earthquake, Soils and Foundations, 52(5), pp.793-810.

Yoshimi, Y. \& Tokimatsu, K. (1977). Settlement of buildings on saturated sand during earthquakes, Soils and Foundations, 17(1), pp.23-38.

White, D. J., Take, W. A. \& Bolton, M. D. (2003). Soil deformation measurement using particle image velocimetry (PIV) and photogrammetry, Géotechnique, 53(7), pp.619-631. 